\title{
Model of Customer Buying Behavior in the CZ Mobile Telecommunication Market
}

\author{
Ondřej Grünwald \\ Dept. of Economics, Management and Humanities, Czech Technical University, Technická 2, 166 27 Praha, Czech \\ Republic \\ Corresponding author: grunwond@fel.cvut.cz
}

\begin{abstract}
The Czech mobile telecommunication market constitutes an oligopoly of three operators, who have built a privileged position and effectively crush any competition. The entry of a new operator has been considered by the government since the end of 2009. The new mobile operator should push down the prices of services, which are the highest in Europe and also affect the development of new mobile services. This paper analyzes consumer behavior in the mobile telecommunication market. It reveals how different elements are considered by customers and what is important when choosing a mobile tariff. With use conjoint analysis, we obtained empirical arguments about the preferences of customers in the Czech Republic. The analysis shows that the relatively high price of services greatly reduces the unsaturated demand in the mobile telecommunication market, and proves that the price is crucial in customer decision-making.
\end{abstract}

Keywords: Model of buying behavior, adaptive choice-based conjoint analysis, market research, market share, price sensitivity.

\section{Introduction}

In present-day market research, the most popular methods for modeling customer buying behavior are discrete-choice methods which include Choice-Based Conjoint (CBC) [6]. These methods are favored mainly for their ability to mimic a real purchasing decision by a discrete choice better than traditional conjoint methods based on ranking or rating a set of product concepts, where customer preferences are usually expressed as rank orders respectively as values on quantitative scales. However, the $\mathrm{CBC}$ approach has been less effective than classical conjoint approaches in the amount of information about preferences that is gathered during questioning[3].

A respondent in a conjoint survey first considers multiattribute product options within some set. In the discrete-choice case, as a result, the respondent chooses just one concept, that is most preferred. The advantage of the choice is that this kind of decision is intuitive for everyone, but several pieces of information concerning the preferential orders of product concepts in the set are not recorded. It is therefore necessary to include more respondents in the CBC interview than in traditional conjoint methods. In recent years, parameter estimation for individual respondents in CBC has become feasible using hierarchical Bayesian methods. However, approaches for designing more effective discrete choice questionnaires are still concern for market researchers.

One method that improves the CBC experiment in terms of effective information gathering [1] is Adaptive Choice-Based Conjoint (ACBC) [5].

\section{Conjoint analysis methodology and experimental design}

Conjoint methods originated in psychometry, and were adopted for market research. Conjoint analysis is in principle based on a global assessment of product incentives described by a specific combination of product attributes. In a questionnaire, respondents make trade-offs among product properties while they consider the overall preference for a concept.

\subsection{The Adaptive Choice-based Conjoint approach}

Adaptive Choice-Based Conjoint (ACBC) is a Sawtooth Software system. It combines two earlier approaches: Choice-Based Conjoint (CBC) and Adaptive Conjoint Analysis (ACA). ACBC has adopted the favorable aspects for questioning. It also allows the analyst to uncover the customer's preferences and to model the customer's buying behavior while he is forming his decision for a complex product or service. During an interview, this approach adjusts the offering of product concepts to make it as relevant as possible for each individual. For each respondent, the specific set of concepts focusing on their decision space is generated. The preference data is analyzed on the individual level, using an HB procedure. Moreover, the ACBC interview method is optimized for a larger number of attributes and levels than was possible in earlier CBC. It is necessary to carry out ACBC 


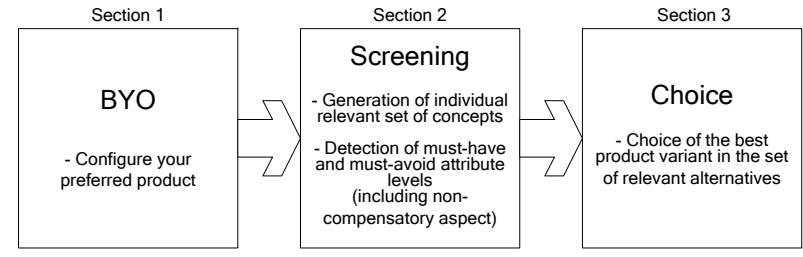

Figure 1: Three ACBC questioning sections.

questioning using a computer, and it is designed in three types of sections, see Figure 1.

The first section is BYO (Build Your Own). Usually, all the attributes and levels included in the interview are presented there, but some of them can be omitted. The respondent chooses the most preferred level from each attribute. In this way, he will define the closest configuration to his ideal product concept. The screening section follows BYO, where the set of respondent's most relevant product concepts (generated as Near-neighbors to BYO) is presented. The algorithm for generating the near-orthogonal set based on BYO selection [3] typically produce $T(18<T<36)$ near concepts containing the full range of attribute levels included in the study. Number $T$ depends on the number of attributes and levels. The algorithm below is executed for each of the $T$ concepts.

Step 1. Randomly choose integer number $A_{i}$ between $A_{\min }$ and $A_{\max }$, which determines how many attributes in $C_{0}$ will be modified to get near to concept $C_{1}$.

Step 2. Randomly choose $A_{i}$ elements in $C_{0}$ which will be modified.

Step 3. Randomly choose levels for the attributes from Step 2 that are not included in the BYO concept.

Step 4. Check that the chosen concept does not contain prohibited pair of levels and does not duplicate a previous respondent's concept. In cases of duplication, or positive detection of a prohibited pair, discard the concept and go back to Step 1 .

In the algorithm, $C_{0}$ is a vector of the number of elements which is equal to the number of attributes in the BYO concept. $A_{\min }$ and $A_{\max }$ are explicitly set during questionnaire design to determine the minimum and maximum number of attributes that can be modified from the BYO concept. The set of generated concepts is presented in the task, usually with 4-6 concepts at once, and the respondent chooses one answer from the two options in each concept. This indicates whether a product of this type is acceptable to him to purchase as a customer. From these responses, we can derive for each respondent the None parameter quantifying a utility threshold within which the respondent is willing to buy. During the purchase decision, customers usually use the elimination method and reduce the set of options from among which the final product will be chosen. ACBC incorporates cutoff rules taking must-have and must-avoid product features [5] into account. The must-have question asks for the attribute levels that were included in the concepts marked as possibility for purchase during the previous screening tasks. The must-avoid question asks in a similar way for the attribute levels that were not presented in any of the product concepts marked as a possible option.

Compensatory models assume, that the utility of concept is $U=\sum_{J} X_{i} \beta_{j}$, where $J$ is the number of attributes in concept $U$ and $\beta_{j}$ is a part-worth parameter that denotes the weight of the utility of attribute level $X_{j}$. These cut-off questions confirm the levels that cannot be compensated in the product by an another level. The set of concepts for the upcoming tasks is adjusted in a way that the concepts containing the must-avoid level, or not containing must-have levels, are replaced by new concepts satisfying the uncovered cut-off rules.

The choice tournament section of ACBC is in sense of discrete choice (one concept among other options within choice task) as in CBC tasks. Here, only the options chosen in the screening section as possible product concepts for purchase are presented to the respondent. In this way, each respondent is asked only to a narrow group of product options that are relevant to him (CBC includes all range of concepts included in an experiment). Usually, this section presents around 3-5 concepts at once, and the concept chosen as the best option is offered again in the subsequent tasks, together with the other winners. This is repeated until only one concept is left. This process takes $t / 2$ choice tasks for $t$ concepts taken from the screening section.

Another special feature of ACBC is the possibility to create a summed price attribute. The classical price attribute approach usually defines $3-5$ levels as discrete points in the price range and combines them with other attribute levels. This causes some of the concepts present unrealistic prices for low-end and premium products (low-end products are shown with a high price level, and vice versa). In this situations, respondents may distribute their preferences in a distorted way. Unlike classical approaches, ACBC composes the concept price as the sum of some common base price with partial component prices assigned to the levels included in the concept. While the concept set for the interview is being generated, the prices in the concepts are generated with a predefined variation [5]. All the attributes in the concepts should be mutually independent, but some small correlation is acceptable in order to achieve highly realistic concepts. For sufficient independence of the price attribute, the 
prices in the concepts should be varied randomly, at least in the range from $-30 \%$ to $30 \%$ from the sum of the static base price with the component prices of concepts.

\section{$2.2 \quad$ Estimation part-worth utilities}

This estimation can be made using the HB procedure $[2,4,7]$, where we want to estimate the part-worth for each individual respondent in vector $\beta$, the mean value of all respondents in vector $\alpha$, variances and covariance for the respondents in matrix $C$. The hierarchical model consists of two levels, the upper level and the lower level. At the upper level, we assume that the vectors of the individual part-worths have multivariate normal distribution.

$$
\beta \sim N(\alpha, C)
$$

At the lower level, we assume a multinomial logit model for each respondent. Probability $p$, that respondent $i$ chooses from set $m$ a particular product alternative $n$ is equal:

$$
p_{i m n}=\frac{\exp \left(X_{m n} \beta_{i}\right)}{\sum_{j=1}^{N} \exp \left(X_{m j} \beta_{i}\right)}
$$

where $N$ is the number of the concept in set $m$. $X_{m n}$ represents vector $(1 \times n)$ of attribute levels of $n$ th alternative from set $m$. The estimation algorithm can be described as:

Init. Based on counts of the presence of the levels in the chosen concepts divided by the count of the presence of the levels in all concepts from set $m$, determine the initial estimate of vector $\beta$, set the elements of $\alpha$ to 0 and, for $C$, set unit variance and zero covariance.

Step 1. Based on the current estimations of $\beta$ and $C$, estimate vector $\alpha$ as the mean value of the distribution.

Step 2. Based on current estimations of $\beta$ and $\alpha$, estimate matrix of variance and covariance $C$.

Step 3. Based on the current estimates of $\alpha$ a $C$, estimate new vector $\beta_{\text {new }}$ for each respondent $i$.

The algorithm is repeated in thousands of iterations which can be divided into two groups. The first few thousand iterations are used to achieve convergence, and the subsequent iterations further refine the estimation. The second group contains the remaining few thousand iterations, which are saved for further analysis and the estimation of vectors $\beta, \alpha$ and $C$. Unlike conventional statistical approaches, the subsequent iterations do not converge to a single point estimate for each part-worth parameter, but after converging the estimates move randomly randomly in the subsequent

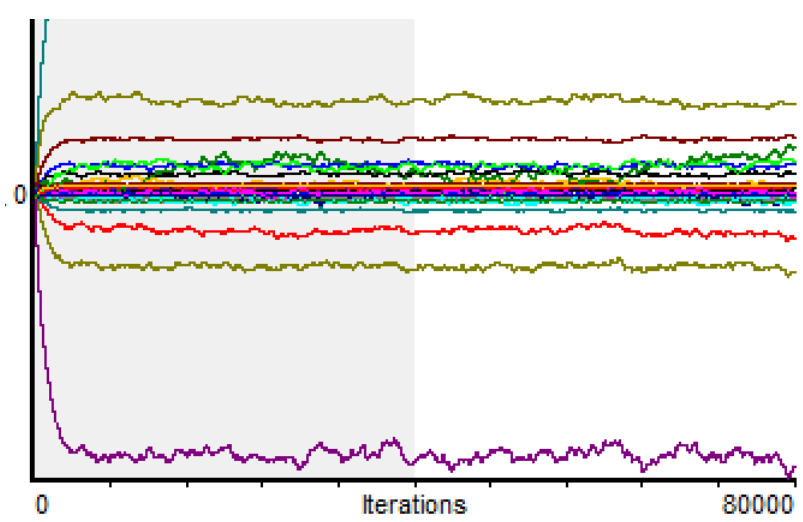

Figure 2: Parameter estimates using HB routine.

iterations which reflect some amount of uncertainty, see on Figure 2.

The part-worths are determined as a point estimate obtained by averaging the individual vectors $\beta$ from the second group of iterations. Subsequent values of $\beta_{\text {new }}$ in each iteration are estimated by using the Metropolis-Hasting algorithm, which shapes the whole estimation process by a Bayesian nature. We assume that $\beta_{\text {old }}$ and $\beta_{\text {new }}$ represent the former and subsequent estimation where vector $\beta_{\text {new }}$ was created by adding a small random variation to $\beta_{\text {old }}$. By using the logit model, we can compute, from vector $\beta$, the probability of occurrence for the choice set of each respondent.

$$
l_{i}=\sum_{m=1}^{M} \sum_{n=1}^{N} y_{i m n}\left(p_{i m n}\right)
$$

In accordance with the hierarchical model, individual vectors $\beta$ have multinomial normal distribution with a mean value $\alpha$ and covariance matrix $C$. Using the relative probability density function in Expression 4 , we can compute the probabilities $p_{\text {new }}$ and $p_{\text {old }}$ that $\beta_{\text {old }}$ and $\beta_{\text {new }}$ would have been drawn from that distribution.

$$
p\left(\beta_{1}, \beta_{2}, \ldots, \beta_{k}\right)=e^{-\frac{1}{2}(\beta-\alpha)^{\top} C^{-1}(\beta-\alpha)}
$$

Finally, we can compute ratios $r$ of the posterior probabilities which are in accordance with the Bayesian rule:

$$
r=\frac{\left(l_{\text {new }} \times p_{\text {new }}\right)}{\left(l_{\text {old }} \times p_{\text {old }}\right)}
$$

If ratio $r$ is greater than 1 , a new estimate of $\beta_{\text {new }}$ is accepted, because it has a higher posterior probability than in the previous step. If $r$ is less than 1 , vector $\beta_{\text {new }}$ is accepted for the next iteration step with probability equal to $r$.

\subsection{ACBC experiment to investigate customer buying behavior}

We tested the ACBC approach in a case study concerned with mobile operator tariffs in the Czech Re- 


\begin{tabular}{lll}
\hline Operator & Calls & SMS \\
\hline New Operator & 50 minutes (CZK 140) & 20 SMS (CZK 20) \\
\hline Vodafone & 150 minutes (CZK 300) & 100 SMS (CZK 60) \\
\hline T-Mobile & 300 minutes (CZK 450) & 500 SMS (CZK 150) \\
\hline Telefónica O2 & 500 minutes (CZK 600) \\
\hline & Unlimited (CZK 1500) & Contract \\
\hline Data & Free numbers & Lump sum (2 years) \\
\hline Without data & Without & Transferable credit \\
\hline 150 MB & 3 free numbers (CZK 150) & Rechargeable card \\
\hline 500 MB & 6 free numbers (CZK 300) & \\
\hline 1 GB & &
\end{tabular}

Price: Summed pricing attribute at different prices from $+50 \%$ to $-30 \%$

Table 1: Attributes and configuration for the ACBC study.

public. The aim of our empirical study was:

1. To test the ability of the ACBC method in terms of its applicability in a real scenario by using an electronic survey.

2. To evaluate the potential chances of a new GSM operator entering the $\mathrm{CZ}$ market in terms of identifying a suitable product offer.

3. To determine the attributes of services offered by the mobile operators in terms of their utility and importance from the perspective of customers.

4. To determine the optimal telephone tariff (a combination of levels of attributes with the highest utilities) for a new operator.

5. To estimate the demand for services of the new operator and to determine customer needs and expectations.

6. To gain an insight into customer buying behavior in mobile telecommunications when deciding the tariff.

7. To design a price sensitivity model.

The study included a total of 7 product attributes with a total of 23 levels $^{1}$, see Table 1 .

\footnotetext{
${ }^{1}$ The attributes and their levels were determined by an analysis of unit prices for services offered by the operators on their websites in November 2011. The BYO component prices were set to reflect the upcoming Christmas event and were generally lower than the official offers. However, the operators have also been broadly offering unofficial individual retention bids at much lower prices.
}

The attribute Operator was not included in the BYO section. The screener section was composed of 7 tasks each consisting of 4 concepts. After 3 initial screening tasks, 3 must-avoid questions and 2 musthave questions about the levels were asked. In the choice tournament section, each task consisted of 3 concepts.

\section{Results of the empirical study}

The experiment ${ }^{2}$ was started the week before Christmas 2011. A total of 816 individual questionnaires were initialized in BYO during the experiment. A typical respondent was a student of a Czech university, aged between 20 and 30. The number of fully completed experiments was 512 , i.e. $63 \%$.

\subsection{Counting analysis of tariff choices}

A counting analysis provides a good insight into the proportion of respondent decisions in each section of the experiment. Figure 3 shows the frequency of the level choices within the attributes while setting up the ideal product in BYO. The operator attribute has been omitted in this section.

Figure 3 shows the most common initial configuration of the desired tariff as a result of trading the attribute levels with associated component prices. The

\footnotetext{
${ }^{2}$ Electronic interviews and the subsequent analysis of data were performed using SSI Web from Sawtooth Software.
} 


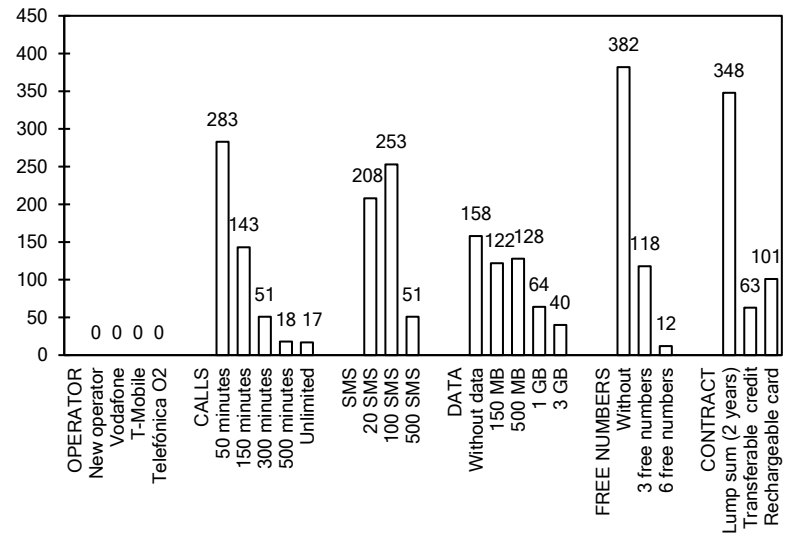

Figure 3: Frequencies of level choices in BYO.

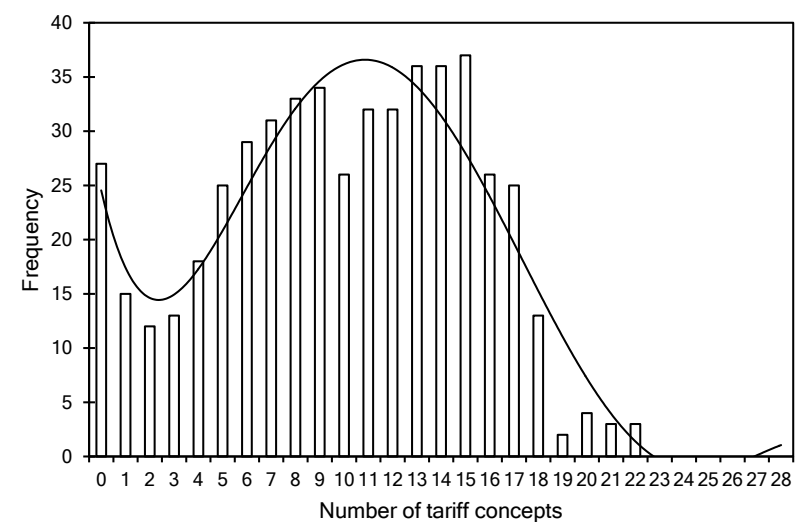

Figure 4: Frequencies of the number of the acceptable concepts.

most configured tariff was: 50 minutes, 100 SMS, without data services, without free call numbers within the network and lump payments for two years. Much emphasis in the selection of respondents was on price, because respondents preferred a level of quantitative attributes at the lowest price. In the following screening section, where a set of tariffs generated as the nearest neighbors to the BYO tariff was presented (each varied in between 1-2 attributes), the respondents considered the variants in means of the options for purchase. The largest group of respondents marked between 7 and 17 concepts as acceptable products. There were also respondents for whom no tariff was acceptable (a total of 27 respondents, representing $5.27 \%$ of the total group). Figure 4 illustrates how many respondents marked how many concepts as their option for the purchase.

In the screening section, two questions on must-have attribute levels and three questions on must-avoid attribute levels were included (non-compensatory aspects). Figure 5 shows the frequency of the respondents' setting must-have levels in a tariff.

The graph shows that the acceptability of the tariffs was mostly conditioned by at least $150 \mathrm{MB}$ of data services (28.32\%), 100 SMS (16.41\%) and 150

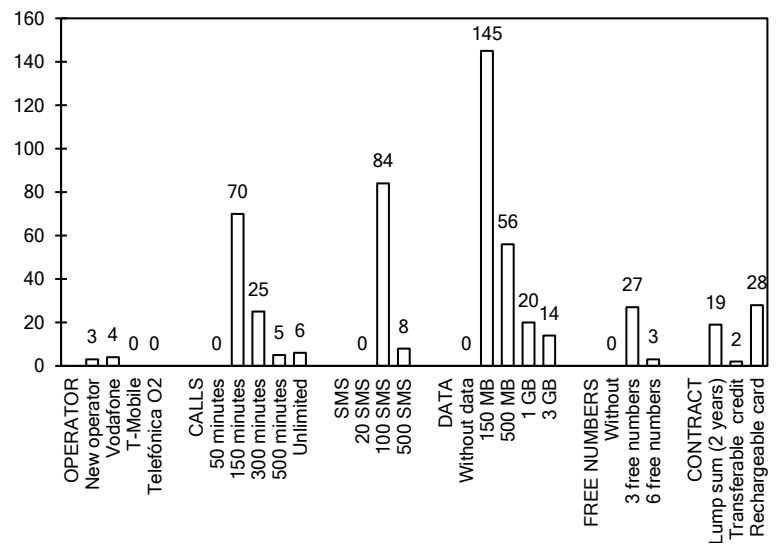

Figure 5: Frequencies of must-have levels.

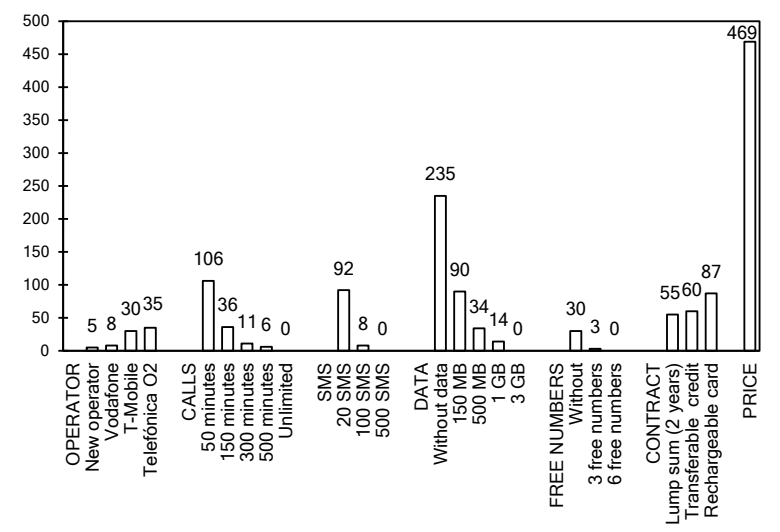

Figure 6: Frequencies of must-avoid levels.

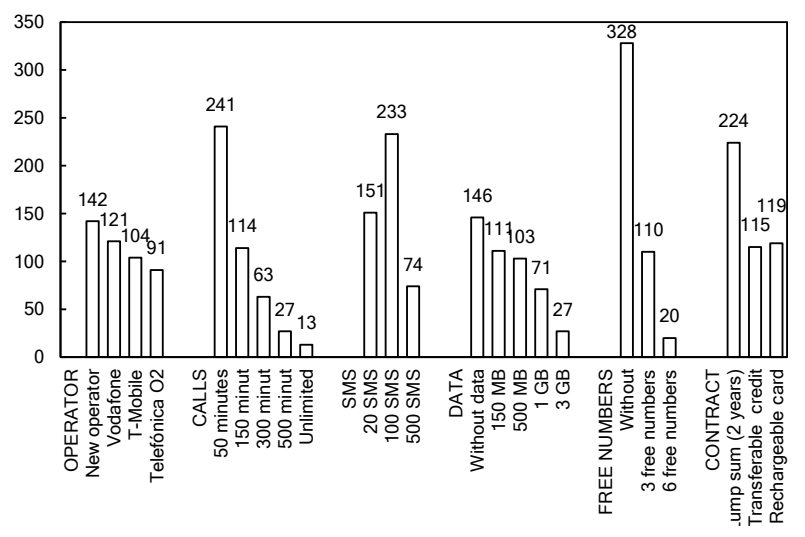

Figure 7: Frequencies of levels in winning concepts.

minutes of voice services $(13.67 \%)$. The difference for the BYO section was mainly due to the predefined variability of the prices leading to more favorable tariffs. Figure 6 shows the frequencies of the second part of the cut-off rule, namely the must-avoid attribute levels of a tariff.

Price level was clearly the most common consideration that was chosen as the must-avoid level. A large proportion of respondents $(91.6 \%)$ limited the tariffs acceptable to them to an average price of CZK 635 


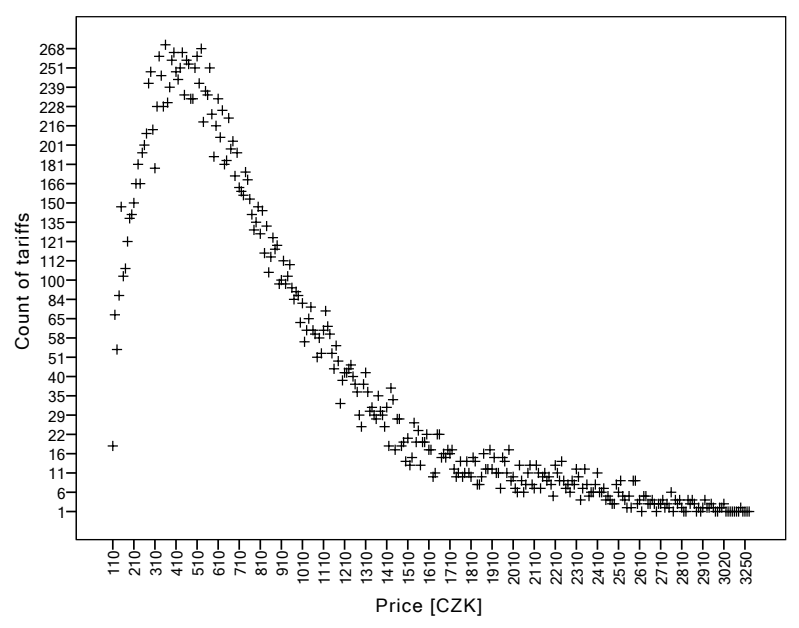

Figure 8: Distribution of tariff prices in screening sections.

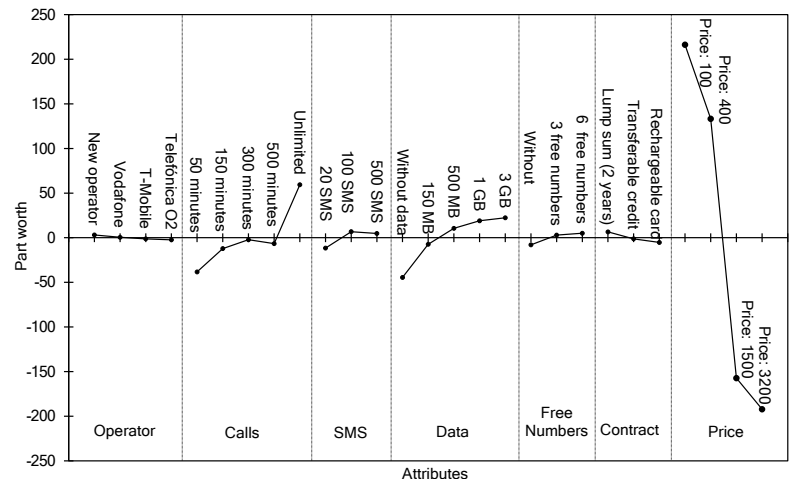

Figure 9: Utility part-worth functions of the tariff attributes.

per month. Another significant part of the respondent group would not accept a tariff without data services $(45.9 \%)$. It is also interesting how many times the operator levels were marked as must-avoid. Especially Telefónica O2 (6.84\%) and T-Mobile (5.86\%) receiving the largest number of disapprovals. The small frequency of the operator attribute in the noncompensatory consideration is obvious here.

Figure 7 refers to the frequency of the levels in the winning concepts of the final questionnaire section, which was chosen by the respondents by selecting the most appropriate concepts in the subsets created from the accepted tariffs from the screening section, where the respondents determined the winning concept.

The most frequent winner would be the New Operator tariff with 50 minutes (52\%), 100 SMS (50.8\%), no data services $(31.88 \%)$, no free numbers $(78.62 \%)$ and Lump monthly payments for two years $(48.91 \%)$. The average tariff price would be CZK 432.

\begin{tabular}{|c|c|c|}
\hline $\begin{array}{l}\text { (Zero-Centered } \\
\text { Differences) }\end{array}$ & $\begin{array}{l}\text { Average } \\
\text { Utilities }\end{array}$ & $\begin{array}{l}\text { Standard } \\
\text { Deviation }\end{array}$ \\
\hline New operator $\left(\beta_{1}\right)$ & 3.1208 & 6.375 \\
\hline Vodafone $\left(\beta_{2}\right)$ & 0.4692 & 6.0899 \\
\hline T-Mobile $\left(\beta_{3}\right)$ & -1.2532 & 5.7165 \\
\hline Telefónica O2 $\left(\beta_{4}\right)$ & -2.3367 & 5.4828 \\
\hline 50 minutes $\left(\beta_{5}\right)$ & -38.3277 & 26.6757 \\
\hline 150 minutes $\left(\beta_{6}\right)$ & -12.1474 & 11.4497 \\
\hline 300 minutes $\left(\beta_{7}\right)$ & -2.274 & 13.2111 \\
\hline 500 minutes $\left(\beta_{8}\right)$ & -6.6355 & 19.0811 \\
\hline Unlimited $\left(\beta_{9}\right)$ & 59.3847 & 24.3779 \\
\hline $20 \operatorname{SMS}\left(\beta_{10}\right)$ & -11.6015 & 17.57 \\
\hline $100 \operatorname{SMS}\left(\beta_{11}\right)$ & 6.815 & 7.5969 \\
\hline $500 \operatorname{SMS}\left(\beta_{12}\right)$ & 4.7865 & 13.8801 \\
\hline Without data $\left(\beta_{13}\right)$ & -44.509 & 34.6875 \\
\hline $150 \mathrm{MB}\left(\beta_{14}\right)$ & -7.3311 & 14.0473 \\
\hline $500 \mathrm{MB}\left(\beta_{15}\right)$ & 10.5313 & 12.6187 \\
\hline $1 \mathrm{~GB}\left(\beta_{16}\right)$ & 18.9618 & 14.9506 \\
\hline $3 \mathrm{~GB}\left(\beta_{17}\right)$ & 22.347 & 21.2323 \\
\hline Without $\left(\beta_{18}\right)$ & -7.9633 & 11.4524 \\
\hline 3 free numbers $\left(\beta_{19}\right)$ & 2.9537 & 8.5123 \\
\hline 6 free numbers $\left(\beta_{20}\right)$ & 5.0095 & 6.4706 \\
\hline $\begin{array}{l}\text { Lump sum } \\
\text { (2 years) }\left(\beta_{21}\right)\end{array}$ & 6.5339 & 9.5482 \\
\hline $\begin{array}{l}\text { Transferable } \\
\text { credit }\left(\beta_{22}\right)\end{array}$ & -1.2356 & 6.1642 \\
\hline $\begin{array}{l}\text { Rechargeable } \\
\text { card } \quad\left(\beta_{23}\right)\end{array}$ & -5.2982 & 11.9827 \\
\hline Price: $100\left(\beta_{24}\right)$ & 216.2966 & 29.955 \\
\hline Price: $400\left(\beta_{25}\right)$ & 133.2723 & 35.3982 \\
\hline Price: $1500\left(\beta_{26}\right)$ & -157.3462 & 74.3023 \\
\hline Price: $3200\left(\beta_{27}\right)$ & -192.2227 & 34.1939 \\
\hline None $\left(\beta_{28}\right)$ & 356.1672 & 170.5967 \\
\hline
\end{tabular}

Table 2: Part-worths of the levels estimated using HB procedure. 


\begin{tabular}{lcrrrrr}
\hline Tariff & Operator & Calls & SMS & Data & Contract & Price \\
\hline TM BAV SE* & T-Mobile & 50 & 100 & 0 & Lump sum & 228 \\
\hline TM BAV SE & T-Mobile & 50 & 100 & 200 & Lump sum & 366 \\
\hline TM Kredit 300 & T-Mobile & 60 & 20 & 0 & Credit & 300 \\
\hline O2 Pohoda* & O2 & 50 & 100 & 0 & Lump sum & 180 \\
\hline O2 Pohoda & O2 & 50 & 100 & 150 & Lump sum & 280 \\
\hline O2 NEON S & O2 & 80 & 20 & 0 & Lump sum & 360 \\
\hline St. na míru* & Vodafone & 50 & 20 & 0 & Lump sum & 150 \\
\hline St. na míru* & Vodafone & 80 & 20 & 150 & Lump sum & 240 \\
\hline Karta na míru & Vodafone & 80 & 20 & 0 & Rech. card & 300 \\
\hline$+{ }_{\text {with data } * \text { student tariff }}$ & & & & &
\end{tabular}

Table 3: Simulation of first scenario including student tariffs.

\subsection{Part-worth preference model}

The parameters of part-worth utilities were estimated by an HB-procedure for each respondent on the individual level and interaction effects between attributes were not taken in consideration.

Given the distribution of tariff prices generated in the screening section, see Figure 8, the levels of the price attribute for the part-worth estimation was set as CZK 100, CZK 400, CZK 1500, CZK 3200 to get a good approximation of the distribution of all generated prices, using linear interpolation of the estimated parameters.

The average result of the parameter estimation using the iterative $\mathrm{HB}$ procedure is contained in Table 2 and is presented graphically in Figure 8, where each attribute level has one parameter $\beta$ estimated. The utilities for individual attributes are zero centered (the sum of the levels of attribute is 0 ), where the levels of mutually independent attributes are interpolated using the linear function.

The range of maximum and minimum part-worth levels in the attribute represents the relative attribute importance computed as the utility range of the single attribute divided by the sum of all attribute ranges. The highest average importance is allocated to the attribute price $(62 \%)$, second place goes to the voice services $(14.7 \%)$ and then comes the data services $(11 \%)$. These attributes have most influence on the customer's buying decision. The slope of the line between the levels within the attribute specifies the size of the change in utility due to a change in the attribute levels in the concept. For example, in voice services, the benefit of the tariff will increase most when the level is changed to unlimited calls.

The parameter "None" (the average value was 356 ) for each individual respondent is derived from answers in the screening section which represents the threshold of the utility at which a purchase is made by the respondent. This parameter for each respondent was used to determine the purchasing decision in the subsequent market simulation model.

\subsection{Simulation model for market scenarios}

The simulation was performed using the market simulator from Sawtooth Software with 9 tariffs in the scenario, see Table 3. The first scenario is based on web tariff offers from operators, and primarily comprise a market of student tariffs due to the composition of the group of target respondents. The student tariffs offer less expensive mobile services than standard tariffs, and the preference data from the respondents reflects the high importance of the price attribute, as seen in the part-worth estimation result in Table 2. At the same time, one standard tariff is added for each operator to obtain a preferential comparison of the utility of the non-student offers.

The result of the market share (preference share) simulation is listed in Table 4 and in Figure 10. The simulation is based on the First Choice rule that supposes each respondent will buy the concept with the highest utility. Despite the favorable prices offered in the student tariffs, nearly half of the respondents $(49.32 \%)$ would not purchase any tariff in this scenario. Table 4 shows that $\mathrm{O} 2(27.93 \%)$ received the largest share in relation to the other offers in this scenario, Vodafone $(16.67 \%)$ had the second largest share and T-Mobile (6.08\%) took third place.

Student tariffs with data services gained the highest 


\begin{tabular}{|c|c|c|}
\hline Tariff & Share $[\%]$ & Std. Err. \\
\hline TM Bav se* & 2.89 & 0.43 \\
\hline $\mathrm{TM} \mathrm{Bav} \mathrm{se}{ }^{+*}$ & 3.13 & 0.42 \\
\hline TM Kredit 300 & 0.06 & 0.02 \\
\hline O2 Pohoda* & 13.02 & 1.16 \\
\hline O2 Pohoda ${ }^{+*}$ & 14.84 & 1.15 \\
\hline O2 NEON S & 0.07 & 0.03 \\
\hline VF Student na míru* & 5.99 & 0.73 \\
\hline VF Student na míru ${ }^{+*}$ & 10.5 & 0.96 \\
\hline VF karta na míru & 0.17 & 0.1 \\
\hline None & 49.32 & 1.71 \\
\hline
\end{tabular}

Table 4: Shares of the potential student and standard tariffs market.

share in the simulation. Standard operator tariffs ${ }^{3}$ that are lightly higher in price than the student tariffs would, take no share, see Figure 10.

Due to the practices of the mobile operators, who in many cases offer retention bids in an attempt to prevent customers transferring to another operator, the New Tariff based on the detected retention offer (operator: A new operator, call: 150 minutes, SMS: 120, data: $600 \mathrm{MB}$, contract: Lump sum (2 years), price: CZK 220) was added to the basic scenario to compute its share, see Table 5.

The simulation results show that only a small proportion of the respondents (14.43\%) would not accept the offer of the New Operator ${ }^{4}$. If a new operator were to enter the market with this tariff, it would acquire the majority of the market $(72.27 \%)$ provided that the other operators did not change their offer.

\subsection{Price sensitivity model}

In the market simulator, we also conducted a price sensitivity test. For each tariff, we gradually changed the price levels, while maintaining the other tariffs at constant settings, and in each step we observed what the change in the proportion of tariff was in the scenario. The results are shown in Figure 11. The degree of price elasticity is usually calculated as:

$$
E=\frac{\frac{q_{2}-q_{1}}{0.5\left(q_{1}+q_{2}\right)}}{\frac{p_{2}-p_{1}}{0.5\left(p_{1}+p_{2}\right)}}
$$

\footnotetext{
${ }^{3}$ Standard tariffs are in tables without marks $*+$

${ }^{4}$ The "New tariff" offer was configured based on a retention offer made by an existing operator.
}

\begin{tabular}{|c|c|c|}
\hline Tariff & Share $[\%]$ & Std. Err. \\
\hline TM Bav se* & 0.97 & 0.19 \\
\hline TM Bav se $+*$ & 0.11 & 0.03 \\
\hline TM Kredit 300 & 0.02 & 0.01 \\
\hline O2 Pohoda* & 6.11 & 0.79 \\
\hline O2 Pohoda ${ }^{+*}$ & 0.74 & 0.17 \\
\hline O2 NEON S & 0.02 & 0.01 \\
\hline VF Student na míru* & 2.97 & 0.47 \\
\hline VF Student na míru ${ }^{+*}$ & 2.22 & 0.40 \\
\hline VF karta na míru & 0.13 & 0.10 \\
\hline New Tariff & 72.27 & 1.47 \\
\hline None & 14.43 & 1.02 \\
\hline
\end{tabular}

${ }^{+}$with data $*_{\text {student tariff }}$

Table 5: The basic scenario with the New Tariff based on the retention proposal.

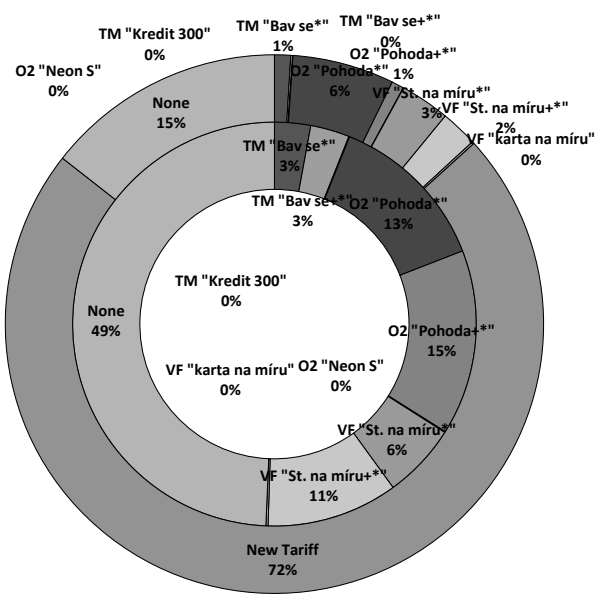

Figure 10: Shares of potential market of student and standard tariffs.

In Figure 11, we estimate the average price elasticity $E$ of the demand using log-log regression, which is more accurate in this case, where there are several price points.

At a price level of CZK 100, the New Tariff would take almost $90 \%$ of the market. When the price increases, the share decreases rapidly and when exceeds a level of CZK 600, the market share of the New Tariff drops to less than $10 \%$. All the student tariffs at the lowest price level of CZK 100 have a market share below $20 \%$. When the price is increased, the share decreases rapidly due to the high price elasticity of the tariffs. Taking into account the current market situation and the price elasticity, if all operators were to 


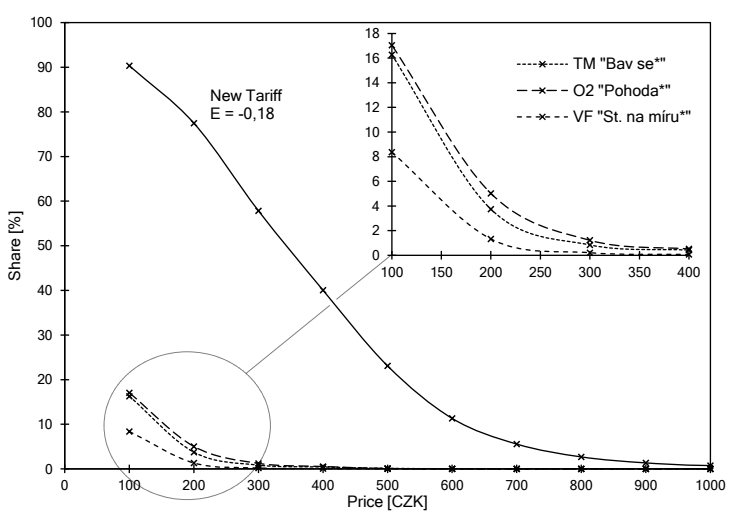

Figure 11: Price sensitivity slopes of tariffs in the second simulation scenario.

reduce their price, the T-Mobile and $\mathrm{O} 2$ tariffs would gain a bigger additional share than the Vodafone tariff. In this model, offering a suitable combination of mobile services is more important than the operator's brand for the respondents' purchasing decision.

\section{Conclusion}

The aim of this paper was to analyze customer preferences for mobile telecommunications services. The study was based on real market information. By using conjoint analysis, we provide a preference model based on empirical customer choice data which confirms that conjoint analysis is very helpful tool to quantify the potential effects of specific aspects of operator tariffs. The market analysis in this study consists of a counting analysis, a part-worth analysis, a choice simulation model and a price sensitivity model. The first analysis provides a view on the extreme values of the elements in the chosen concepts. The analysis of the part-worth utilities is created on the basis of a logit model, which takes into account all the respondent answers for the parameter estimation. This model allows us to predict the buying behavior and the preference of any respondent for any possible combination of the attributes involved in the study. The subsequent simulation model was analyzed in two basic scenarios including student tariffs, and their market shares (their preferences) were estimated. Finally, we compiled a price sensitivity model.

The key finding of the study is based on an analysis of prices. These findings confirmed that the price range, which was also most often restricted by respondents as a non-compensatory consideration, is the most important factor involved in the final purchasing decision made by customers, who are willing to significantly reduce the range of services for witch they subscribe, in return for a lower price. In the Czech Republic, the tariff prices are above the European average, and customers can easily compare the prices with offers abroad. This renders the current operators' offers of little interest, and customers often negotiate better prices through unofficial retention deals. The entry of a new operator into the market with favorable prices promoted in official offers would surely reduce the current high prices for services. However, the new operator will have to anticipate an aggressive pricing strategy of the three present day operators in response to the new competition.

\section{Acknowledgements}

The research described in this paper was supervised by doc. Ing. Věra Vávrová, CSc., FEE CTU in Prague and supported by Sawtooth Software under grant No. 1303744 and No. 1303744 b.

The author would like to thank Sawtooth Software for the grant for software licences and Doc. Ing. Věra Vávrová, CSc. for insightful and constructive comments.

\section{References}

[1] C. Chapman, J. Johnson, C. Weidemann et al. CBC vs. ACBC: Comparing Results with Real Product Selection. In Sawtooth Software Conference Proceedings, Sequim, WA, 2009.

[2] R. Johnson. Understanding HB: An Intuitive Approach. Research Paper Series, Sawtooth Software, 2000 .

[3] R. Johnson, B. K. Orme. A New Approach to Adaptive CBC. In Sawtooth Software Conference Proceedings, Sequim, WA, 2007.

[4] T. Otter. HB Analysis for Multi-Format Adaptive CBC. In Sawtooth Software Conference Proceedings, 2007, p. 111.

[5] Sawtooth Sofware Inc. ACBC Technical Paper, 2008. Technical paper series.

[6] Sawtooth Sofware Inc. The CBC System for Choice-Based Conjoint Analysis, 2008. Technical paper series.

[7] Sawtooth Sofware Inc. The CBC/HB System for hierarchical Bayes Estimation Version 5.0, 2009. Technical paper series. 